Anales de Geografía de la Universidad Complutense ISSN: 0211-9803

http://dx.doi.org/10.5209/rev_AGUC.2016.v36.n1.52714

\title{
Los orígenes del turismo en la Isla de la Palma: La década de los sesenta del siglo XX
}

\author{
José Ángel Hernández Luis ${ }^{1}$; Alejandro González Morales²; Juan Manuel Parreño Castellano ${ }^{3}$ \\ Recibido: 24 de julio del 2015 / Enviado a evaluar: 23 de enero del 2016 / Aceptado: 3 de mayo del 2016
}

\begin{abstract}
Resumen. La década de los sesenta fue una etapa de gran interés para el desarrollo turístico de la isla de La Palma. Varias iniciativas de carácter público y privado, como el impulso para la construcción de un nuevo aeropuerto, diversas urbanizaciones, el plan turístico del Cabildo de 1968 o también la creación de la entidad pública "La Palma, Sociedad Anónima de Turismo" en 1969, constituirán los pilares básicos del futuro desarrollo del turismo en la Isla y serán el resultado del empuje a las inversiones privadas en este sector económico. En la década de los sesenta, ya se habían materializado dos hoteles, mientras que al menos otros tres más, superiores al centenar de plazas cada uno, quedaron inacabados.
\end{abstract}

Palabras clave: Desarrollo turístico; políticas turísticas; isla de La Palma; transporte exterior; prensa.

\section{[en] The beginning of tourism in La Palma Island: Sixty years of the XX century}

Abstract. The sixties was a time of great interest for tourism development on the La Palma island. Various actions of public and private, as the policy of building a new airport, various tourist resorts, the tourism plan of 1968 or insular government also creating public entity "La Palma, Tourism SA" in 1969, will be the basis for future development of tourism on the island and will result push for private investment in this economic sector. Indeed, in the sixties, private investors had opened two hotels, while at least three others over a hundred beds each, weren't finished.

Key words: Tourism development; tourism policies; La Palma island; external transport; newspapers.

1 Departamento de Geografía. Universidad de Las Palmas de Gran Canaria.

E-mail: jose.hernandez@ulpgc.es

2 Departamento de Geografía. Universidad de Las Palmas de Gran Canaria.

E-mail: alejandro.gonzalez@ulpgc.es

3 Departamento de Geografía. Universidad de Las Palmas de Gran Canaria.

E-mail: juan.parreno@ulpgc.es 


\section{[fr] Les origenes du tourisme dans l’ile de La Palma: Les sisties du XXe Siècle}

Résumé. Les années soixante a été un moment de grand intérêt pour le développement du tourisme sur l'île de La Palma. Plusieurs initiatives de public et privé, que l'impulsion pour la construction d'un nouvel aéroport, plusieurs stations touristiques, plan de tourisme Cabildo 1968 et aussi la création de l'organisation publique "La Palma, SA Tourisme" en 1969 sera le résultat de la poussée de l'investissement privé dans ce domaine. Ainsi, dans les années soixante, avait concrétisé deux hôtels, tandis qu'au moins trois autres plus d'une centaine sièges chacun, ont été laissées en suspens.

Mots Clès: Développement touristique; les politiques du tourisme; l'île de La Palma; insularité; journaux touristiques.

Cómo citar. Hernández Luis, J.A., González Morales, A. y Parreño Castellano. (2016): Los orígenes del turismo en la Isla de la Palma: La década de los sesenta del siglo XX. Anales de Geografía de la Universidad Complutense, 36(1), 71-90.

Sumario. 1. Introducción. 2. El fracaso de las iniciativas turísticas de carácter público. 2.1. El plan turístico de "La Palma y el Mar”. 2.2. Las aspiraciones de la "Costa Gris”. 2.3. El desarrollo turístico de la "Costa de Tazacorte". 2.4. Plan turístico del Cabildo Insular de 1968. 3. El escaso desarrollo de la iniciativa privada. 4. Causas del fracaso del modelo turístico en los años sesenta. 4.1. La rentabilidad de la actividad primaria. 4.2. El hándicap del transporte exterior. 5. Conclusiones. 6. Bibliografía.

\section{Introducción}

Desde finales de los años cincuenta y durante la siguiente década, se acometieron en España varias iniciativas públicas con el objeto de potenciar el desarrollo turístico (Gaviria, 1974; Terán Troyano, 1978; Bayón Mariné, 1987; Fernández Fúster, 1991; Blasco, 2001; Velasco, 2004; Moreno Garrido, 2007; Puertas, 2007; Hernández Luis, 2008; González Lemus, 2012; Faraldo y Rodríguez-López, 2013; Murray, 2015).

Algunas medidas de política económica supusieron sentar las bases necesarias para la eclosión turística en el país. El ingreso de España en la Organización de Naciones Unidas (1955), en el Fondo Monetario Internacional (1958) y en la Organización Europea de Cooperación Económica (1959) junto con la puesta en marcha este último año del Plan de Estabilización Económica de Ullastres, con el objetivo, entre otros, de mejorar la balanza de pagos, permitió la potenciación del turismo y una mayor permisividad de las inversiones extranjeras en España (Casanova, 1970; Cals Güel, 1974; Pellerejo Martínez, 1999; Esteve Secall, 2000; Almeida García, 2012; Murray, 2015). A todo ello se sumó una política de suelo y de estímulo turístico que potenció las inversiones turísticas, como la Ley de Centros y Zonas de Interés Turístico Nacional de 1963, que reglamentaba las intervenciones urbanas en dichos espacios; la creación de la Empresa Nacional de Turismo ese mismo año, con el objetivo de potenciar la construcción de alojamientos y todos los servicios complementarios (Bayón Mariné, 1999, Vallejo Pousada, 2002) y la Orden de 1965 por la que se regulaba el Crédito Hotelero y la Ayuda para Construcciones Turísticas, que supuso el impulso decisivo al sector, pues facilitaba aún más la tarea a la iniciativa privada en materia de construcción, ampliación, modernización y transformación de los diversos establecimientos (de alojamiento, restaurantes, 
mobiliario y de "cualquier otra construcción que pudiese considerarse necesaria o de repercusión en actividades turísticas") ${ }^{4}$.

A esta política se le unirían los Planes de Desarrollo desde 1964 que, sobre todo, se plasmarían en las actuaciones para potenciar los planes de carreteras y aeropuertos, además de abordar los principales problemas para el desarrollo del turismo. Entre las dificultades turísticas más importantes que se apuntaban en el I Plan de Desarrollo (1964-67), estaba la carencia de alojamientos en las Islas, las deficientes conexiones marítimas, una pésima infraestructura viaria, ausencia de planes de ordenación, escasez de agua, insuficiente promoción y de personal especializado y una estacionalidad muy elevada, factores que no permitían un aprovechamiento óptimo de la oferta durante todo el año (Organización Sindical, 1963).

Las iniciativas turísticas estatales propiciaron que cada vez más Canarias -y en particular la sociedad de La Palma-, se interesaran por desarrollar la actividad turística. Importante también fue la declaración del Archipiélago Canario, en enero de 1963, como Zona de Interés Turístico Nacional. Esta declaración conllevó ventajas muy significativas, por cuanto las Islas recibirían capitales del Estado para adecuar las infraestructuras de apoyo al turismo, así como una mayor permisividad en la política del crédito hotelero para el inversionista particular o en sociedad (Rodríguez Mateo, 1982; Galiana Martín y Barrado Timón, 2006).

Estas políticas también tuvieron su efecto en la isla de La Palma, pues algunos de los inversores locales y foráneos intentaron emprender acciones al mismo tiempo que las autoridades locales concretaban planes y actuaciones. No obstante, el resultado no fue el que cabía esperar. Ni mucho menos comparable a lo que estaba ocurriendo en otras islas como Tenerife o Gran Canaria (Martín Martín, 2000; Hernández Luis y Parreño Castellano, 2002; González Lemus et al., 2012).

Pues bien, el objetivo principal de este artículo es analizar los primeros intentos de desarrollo turístico en la isla de La Palma durante los sesenta y principios de los setenta con el fin de comprender los motivos por los que en la isla no terminó de consolidarse un modelo turístico como los de Tenerife, Gran Canaria o Lanzarote. Se podría pues, contextualizar este marco espacial dentro de las terceras periferias turísticas, como un buen modelo de intento frustrado de desarrollo turístico, por lo menos en el período investigado.

Nuestra hipótesis de partida es que el escaso éxito de las actuaciones públicas y privadas no se debió tanto a factores de falta de inversión, pero si a problemas de conectividad de la isla, sobre todo con el exterior, así como la falta de suelo por la elevada rentabilidad del plátano.

Para ello, la metodología propuesta se fundamenta en el análisis empírico, apoyado en documentos escritos, utilizando sobre todo la prensa y las revistas especializadas en turismo, sin olvidar la bibliografía técnica en este campo y que, para

4 Según se estipulaba en la Orden de 20 de octubre de 1965 por el que se Regula el Crédito Hotelero y la Ayuda para Construcciones Turísticas (B.O.E., 29 de octubre de 1965, artículo 1, apartado c.). 
la Isla de nuestro estudio, se puede considerar relativamente exigua debido al escaso interés turístico que aún ha adquirido la isla de La Palma en relación con las islas centrales y orientales del Archipiélago canario.

De igual modo, aunque hemos optado por darle mayor énfasis al análisis diacrónico, no olvidamos el sincrónico, en tanto que algunas políticas, como por ejemplo la de mejora de las carreteras, la construcción de un segundo aeropuerto, la visita de varias autoridades en aras de potenciar la actividad turística, etc., van a propiciar un fuerte sentimiento a favor del turismo en momentos muy concretos. Hacemos especial hincapié en el análisis de la prensa escrita, pues ésta recoge el sentir popular del fenómeno turístico en la Isla, aunque tomamos estos pareceres con todas las cautelas posibles y en ningún caso como verdades absolutas. De todos modos, el sentimiento de la sociedad de la isla de La Palma, plasmada en su prensa sobre todo a través del Diario de Avisos, único periódico que se editaba en la Isla en los años sesenta-, promovió aún más si cabe, las acciones públicas y privadas en aras de potenciar el turismo en la Isla, por lo que el análisis a fondo de esta rotativa resultó ser indispensable para los resultados de este trabajo.

De igual modo, la consulta de documentos tan importantes como los de la ordenación de las urbanizaciones turísticas: "La Palma y el Mar"; el de la "Costa Gris"; o también el de la "Costa de Tazacorte", al igual que el plan turístico del Cabildo de 1968 o también los estatutos de la entidad pública "La Palma, Sociedad Anónima de Turismo" en 1969, fueron indispensables para la elaboración de este trabajo, todos ellos consultados en el Archivo General del Cabildo Insular de La Palma.

El artículo se ha estructurado en cinco epígrafes principales. Tras esta introducción en la que se presentan el objetivo, la hipótesis y la metodología, se introducen en los epígrafes segundo y tercero las principales iniciativas públicas y privadas que sentaron las bases del despegue turístico de la Isla -o al menos el sentimiento de desarrollo del turismo- en los años posteriores. En el siguiente epígrafe analizamos los principales factores que nos permiten explicar la falta de éxito del modelo turístico de masas en los sesenta y principios de los setenta en La Palma, para acabar con un capítulo final de conclusiones.

\section{El fracaso de Las iniciativas turísticas de carácter público}

Al albor del incipiente desarrollo turístico de principios de los sesenta en otras islas del Archipiélago, desde esos años se presentan, auspiciados por la administración local, los primeros proyectos puntuales de desarrollo turístico en la isla de La Palma. Se trata de las urbanizaciones turísticas de "La Palma y el Mar", "Costa de Tazacorte” y "Costa Gris”. La falta de materialización de estos primeros proyectos motivó que a finales de los sesenta, en el momento en que el urbanismo turístico alcanzaba sus mayores cotas en Canarias, el Cabildo Insular de La Palma presentara el primer plan turístico para el conjunto de la isla y que impulsara la creación de la 
sociedad "La Palma, Sociedad Anónima de Turismo (PALMATUR)", con el fin de buscar las necesarias líneas de inversión. Como había ocurrido en el primer lustro de los sesenta, esta iniciativa no tuvo el éxito que se pretendía, de tal modo que cuando sobrevino la crisis económica de mediados de los setenta, La Palma no había conseguido consolidarse como un destino turístico de masas. A continuación presentamos de un modo más detallado las diferentes iniciativas públicas que acabamos de mencionar.

Figura 1. Localización de las principales propuestas turísticas en los años sesenta en La Palma.

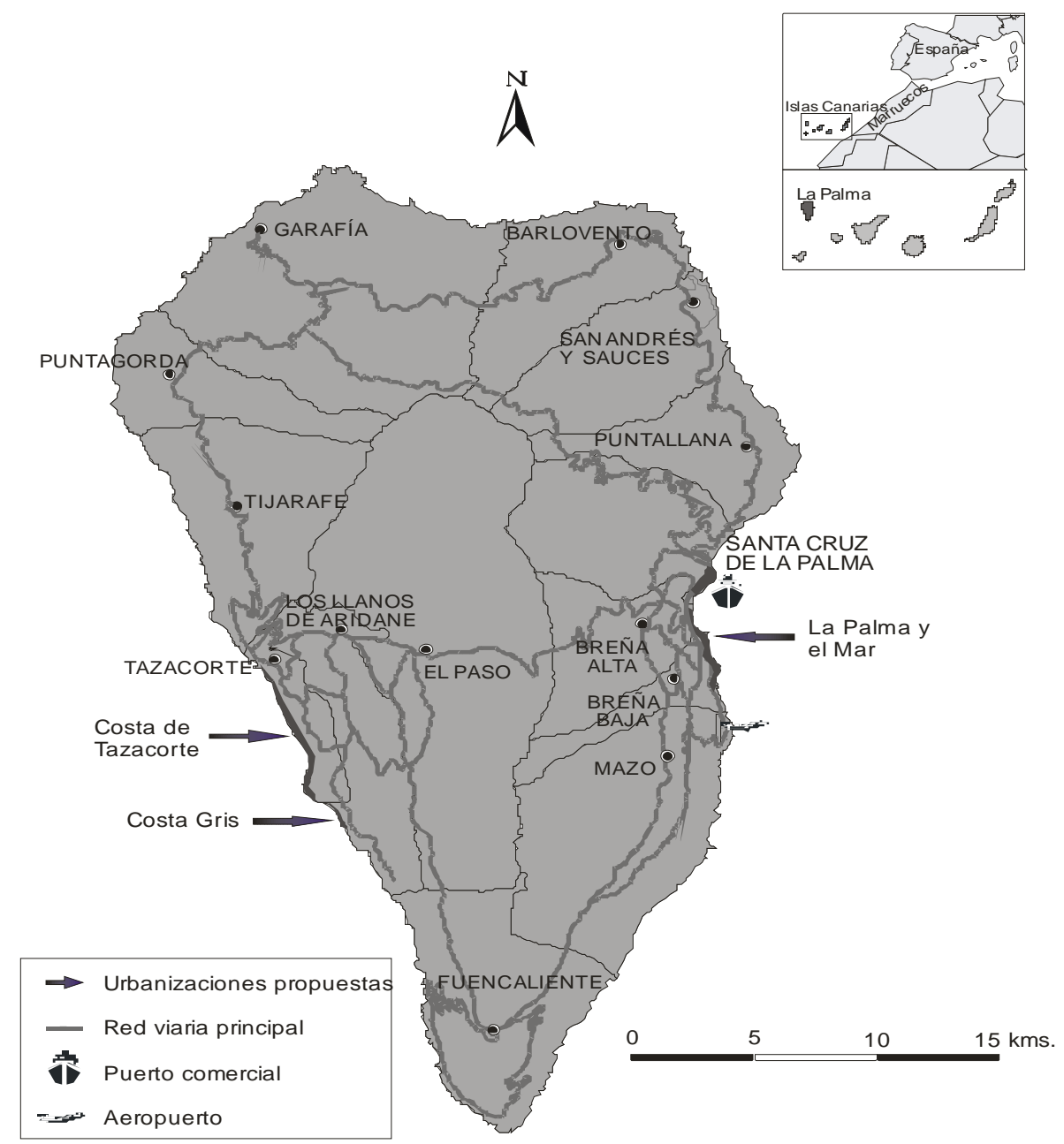

Fuente: Archivo General del Cabildo Insular de La Palma. Elaboración propia. 


\subsection{El plan turístico de "La Palma y el Mar"}

En agosto de 1962, el arquitecto palmero residente en Madrid, D. Pelayo López y Martín Romero, presentó en el Cabildo Insular de La Palma una instancia por el que exhortaba a construir una urbanización turística de un kilómetro de longitud al Sur de la Capital de la Isla y que, con el paso del tiempo, pasaría a denominarse "La Palma y el Mar”. El modelo a seguir partía de las ya desarrolladas por aquélla época, ciudades turísticas del Puerto de La Cruz y Bajamar, en Tenerife, vinculando la urbanización al océano (González Lemus, 2010). Bien es verdad que el arquitecto era parte interesada -en calidad de propietario-, de una buena porción de suelo en este enclave, pero sin duda el paraje era idóneo por su cercanía al mar, a la capital insular, así como a las infraestructuras de transporte exterior.

Pues bien, el arquitecto no sólo presentó la idea ante el Cabildo Insular, sino también en el Ayuntamiento de Breña Baja, donde en gran medida se enclavaba este proyecto. La respuesta que obtuvo fue muy entusiasta por parte de esta última institución, hasta el punto que el Ayuntamiento planificó extender dicha urbanización hasta la Caleta del Palo (Diario de Avisos, 11/09/1962). Ello suponía algo más de tres kilómetros de costa, englobando la actual urbanización turística de Los Cancajos.

El proyecto fue presentado formalmente en el Cabildo Insular de La Palma en diciembre de 1962, con una extensión de 110 hectáreas (tres kilómetros de longitud y un ancho entre 100 y 500 metros), en concreto entre el denominado Risco de La Concepción y la mencionada urbanización de Los Cancajos inclusive ${ }^{5}$. Al final, el proyecto sólo se materializó en el paraje conocido como la playa de Los Cancajos, terminándose allí los primeros bungalows a comienzos de los años setenta y ocupando en la actualidad unas 25 hectáreas.

\subsection{Las aspiraciones de la "Costa Gris"}

En noviembre de 1962, Santa Cruz de La Palma fue sede durante tres jornadas de la $I$ Asamblea Turística de Canarias, asistiendo numerosos profesionales del turismo de las Islas -en especial directores de hoteles y de agencias de viaje-, así como personalidades con cargos públicos, entre los que cabría destacar varios presidentes de los Cabildos Insulares del Archipiélago. En particular, tendríamos que reseñar al Presidente del Cabildo Insular de Tenerife, D. Isidoro Luz Carpenter que, durante los años cincuenta había sido alcalde del importante municipio turístico del Puerto de La Cruz, en la citada Isla. Durante su gestión, en concreto en 1958, se aprobó el Plan General de Ordenación Urbana de este municipio (González Lemus et al., 2012), posibilitando el turismo en el municipio y, por ende, un pionero del desarrollo turístico no solo de Tenerife, sino también de Canarias.

Proyecto de “La Palma y el mar, estación turística”, diciembre de 1962. Archivo General del Cabildo de La Palma, sin paginar. 
En una de las jornadas, los congresistas se trasladaron a la costa occidental de la Isla, a la playa de Puerto Naos que, quizá por extensión y calidad de sus arenas, así como inmejorable clima, es una de las mejores playas de La Palma. Todos los congresistas coincidieron en que este espacio era magnífico para el desarrollo del turismo en la Isla, máxime cuando avanzada la estación otoñal, el clima casi seguía siendo veraniego (Diario de Avisos, 24/11/1962). Por tanto, no es de extrañar que cuando el Ministro de Información y Turismo, D. Manuel Fraga Iribarne, visitó La Palma en septiembre de 1964, el plan de la "Costa Gris" le fue expuesto in situ. Para ello, se habilitó un espacio en el margen de la carretera -desde el que era perfectamente visible aquel territorio- y que abarcaba la playa de Puerto Naos, la del Charco Verde y Las Hoyas. En dicho lugar se expuso una detallada exposición cartográfica y planimétrica, acompañada de una maqueta, para que el señor Fraga Iribarne y el personal técnico que le acompañaba, estudiasen las cualidades que para el turismo tenía aquel paraje (Diario de Avisos, 21/09/1964).

En 1967 se inició la construcción del primer complejo hotelero en la zona, en concreto en la playa de Puerto Naos, cuyo inversor era el Grupo "Las Vegas, S. A.", que ya en 1959 había abierto en el Puerto de La Cruz una de sus primeras instalaciones hoteleras (Canarias Gráfica, 01/11/1968). El hotel, planificado para albergar casi 200 camas, no llegó a terminarse y su estructura permaneció en pie hasta avanzados los años ochenta en que se derribó y construyó uno nuevo.

\subsection{El desarrollo turístico de la "Costa de Tazacorte"}

Escasos días antes de que el Ministro de Información y Turismo visitara La Palma en 1964, se dio a conocer el ambicioso proyecto de urbanización turística de la costa de Tazacorte, un espacio de muy alta productividad agrícola. El proyecto, realizado por D. Rodrigo Rodríguez, perito industrial y exportador de frutos, fue terminado en ese mismo año y pretendía construir una gran urbanización de 30 hectáreas de marcado carácter lineal (siete kilómetros de longitud por 40 - 50 metros de ancho). El proyecto se planificó sobre un acantilado costero elevado entre 50 y 100 metros sobre el nivel del mar, constituyéndose como un auténtico mirador. En la exposición de motivos, el proyecto argumentaba en su memoria que el clima era inmejorable para los turistas, pues las condiciones eólicas eran muy buenas, es decir, con escasez de viento, con una temperatura media entre 20 y 25 grados centígrados, baja pluviometría y, sobre todo, resaltando que este enclave era el de mayor insolación de toda la Isla ${ }^{6}$.

El proyecto propuesto significaba una urbanización de cierta calidad, en el que destacaba la baja densidad de camas por unidad de superficie. El elemento dominante era el paseo marítimo, mientras que detrás se situaba una calle de dos carriles y seis metros de ancho y a continuación otros tres metros de acera con palmeras, para luego

6 Proyecto de “Urbanización turística en la costa de Tazacorte. Isla de San Miguel de La Palma, Canarias”, junio de 1964. Archivo General del Cabildo de La Palma, sin paginar. 
seguir hacia atrás con 20 ó 30 metros de infraestructuras turísticas (hoteles, supermercados, etc.). Además, cada 500 metros aproximadamente, se preveían construir unas escalinatas hasta la playa, en el que la vegetación jugaba un papel fundamental. También se pensó en unos pequeños funiculares con el fin de evitar el fatigoso ascenso desde el $\mathrm{mar}^{7}$.

Se aseveraba que, con la ejecución de la urbanización, la revalorización de todo este espacio sería muy importante, insinuándose en la prensa de la época en estos términos: "tenemos plena certeza de que en esta zona se revalorizarían" (las parcelas) "de una manera asombrosa, y cada propietario de esta mina turística podría edificar o vender -directamente- su respectivo terreno"; proponiéndose también ceder este territorio a cualquier compañía nacional o extranjera que acometiese las obras de urbanización (Diario de Avisos, 16/09/1964).

Al final, el proyecto quedó aparcado sine die, aunque de manera reciente han surgido planes de ordenación bastante más puntuales para este enclave costero de la Isla.

\subsection{Plan turístico del Cabildo Insular de 1968}

Ante la escasa materialización de las propuestas descritas, en septiembre de 1968, el Cabildo Insular dio a conocer una gran iniciativa para el fomento definitivo del turismo. Se trataba de un Plan que llevaba por título: "Bases para un proyecto de planificación y promoción turística de la isla de La Palma, Provincia de Santa Cruz de Tenerife, Islas Canarias".

En las citadas "Bases", y que hemos rescatado del Archivo del Cabildo Insular de La Palma, se marcaban varios objetivos, entre ellos la promoción turística de la Isla. De este modo, el 19 de diciembre de 1968, se presentó en el Parador Nacional de Turismo de Santa Cruz de La Palma, una espectacular guía de la Isla, que constaba de unas 28 páginas y una tirada de 100 mil ejemplares en distintos idiomas, es decir, con una difusión al mismo nivel de las guías que se estaban editando en Tenerife y Gran Canaria (Diario de Avisos, 18/12/1968).

Pero quizá lo más importante de estas “Bases”, es que se definían cuatro territorios de actuación, coincidiendo con los puntos cardinales, en un afán por incrementar y dispersar en el territorio el desarrollo turístico, a saber:

\section{San Andrés y Sauces (Norte de la Isla):}

A): En Puerto Espíndola, instalación deportiva para la pesca, incluyendo varios restaurantes y un alojamiento para una docena de plazas.

B): En Los Tiles, instalación hostelera y deportiva. El alojamiento aquí referenciado alcanzaría una docena de plazas en cabañas. 
2. Santa Cruz de La Palma y Breña Baja (Este de la Isla):

A): Construcción de un gran hotel en Santa Cruz de La Palma, con una categoría de Primera A y con al menos cien habitaciones ampliables a doscientas.

B): Construcción de un restaurante de lujo y sala de fiesta junto al Mirador del Risco de la Concepción.

C): En la playa de Los Cancajos, construcción de un hotel de doscientas habitaciones con categoría de Primera A.

3. Fuencaliente (Sur de la Isla):

A): Proyección de un complejo urbanístico en el extremo Sur de la Isla. Allí iría ubicado un hotel con categoría de Primera A, con capacidad para unas 100 habitaciones.

B): En dicha urbanización, también se planificaban chalets, bungalows y apartamentos.

\section{Los Llanos de Aridane, El Paso y Tazacorte (Oeste de la Isla):}

A): Albergue de 24 habitaciones, un gran restaurante y mirador en La Cumbrecita.

B): Campo de golf de 18 hoyos en el Llano de Las Cuevas.

C): Reiniciar las obras del Hotel Gazmira, en Los Llanos de Aridane. Este hotel, de Primera A, se inauguraría con 50 habitaciones, ampliables a cien.

D): Construcción de un apartahotel de 50 habitaciones en el Puerto de Tazacorte, ampliable sucesivamente.

E): Adquisición de una flota para la pesca deportiva, así como para excursiones, teniendo como base el Puerto de Tazacorte.

El plan implicaba la incorporación de algo más de 1.100 camas turísticas en su pleno desarrollo (excluyendo las plazas de los apartamentos y bungalows de Fuencaliente), que se venían a añadir a las aproximadamente 200 ya existentes en toda la Isla, con una clara concentración en las comarcas de Las Breñas y Santa Cruz de La Palma, seguida del Valle de Aridane.

En suma, fue un ambicioso proyecto que se apoyaba, además de en el acuerdo con la Dirección General de Turismo para mejorar la información turística en la isla (El Eco de Canarias, 14/06/1969), en la creación de la empresa: "La Palma, Sociedad Anónima de Turismo (PALMATUR)”.Esta Sociedad se constituyó en Santa Cruz de La Palma el 01 de julio de 1969, con el patrocinio del propio Cabildo Insular y la extinta Caja de Ahorros Insular de La Palma. El Cabildo se comprometía a suscribir una participación del capital a modo simbólico, para así apoyar la imagen de promoción de dicha Sociedad, en especial en el exterior a la vez que establecía primas de estímulo -o subvención-, para las instalaciones hoteleras previstas en el Plan. La Caja de Ahorros, por su lado, con la misma finalidad y sentido que el Cabildo, respaldaría el patrocinio aportando un mayor crédito. 
El capital insular también podría quedar fuertemente interesado y representado en esta Sociedad, mediante las aportaciones que hicieran los particulares y municipios para la adquisición del suelo, valoradas en acciones que quedarían tanto suscritas como desembolsadas en el momento de la cesión realizada a favor de la Sociedad. El capital restante sería necesario obtenerlo a través de una intensa campaña de promoción de inversionistas, a realizar sobre todo en aquéllas áreas del resto del Estado que por haber alcanzado un fuerte desarrollo -e incluso saturación turística-, dispondrían de capitales y experiencia para trasladar sus caudales a otros espacios de incipiente desarrollo. Es sintomático que la Vicepresidencia de la Junta recayera en D. Vicente Alcina Roselló, decano de las empresas hoteleras y del transporte de Palma de Mallorca, y que había manifestado su convencimiento del porvenir turístico de La Palma (Costa Canaria, 30/12/1969). Su máximo dirigente fue el mismo Presidente del Cabildo Insular, D. Manuel Pérez Acosta, político éste que jugó un papel tan destacado para el desarrollo turístico de la Isla, como el que tuvo su homólogo y coetáneo de Lanzarote, D. José Ramírez Cerdá (González Morales y Hernández Luis, 2005), permaneciendo ambos en el cargo unos catorce años.

Aunque la Sociedad, como decíamos, quedó constituida el 01 de julio de 1969, sus estatutos no se aprobaron hasta el 26 de agosto de 1969. Es importante exponer los principales objetivos de este Organismo como aparecen en sus Estatutos, en tanto que se identificaron de pleno con el desarrollo turístico insular. En concreto, en el artículo dos se dice:

La Sociedad tendrá por objeto principal la construcción, ampliación y explotación de hoteles y cuantas actividades propias, coetáneas y posteriores sean convenientes a aquella finalidad, como compraventas de terrenos, su urbanización en su caso, enajenación de parcelas sobrantes, obtención de créditos personales y reales, adquisición de materiales, aparatos, maquinarias, menajes e instalaciones convenientes al mejor desarrollo de su finalidad propia y cualquiera otra actividad turísticas semejantes.

De igual modo, en el artículo 34, se sentaban las bases para apoyar las inversiones públicas y privadas de naturaleza turística, ayudando en la gestión de los trámites burocráticos que implicaban las transacciones de parcelas, edificios, etc. De modo literal se dice que era objeto de la Sociedad:

Celebrar, contraer y autorizar todo género de actos, obligaciones y contratos sobre cualquier clase de bienes y derechos, mediante los pactos y condiciones que tenga por conveniente, celebrando compras, ventas, permutas, préstamos, anticipos, arrendamientos y constitución de sociedades; adquirir y enajenar inmuebles y derechos reales, gravar unos y otros, cancelar hipotecas; solicitar, explotar y adquirir y enajenar bienes y negocios; fijar los precios y condiciones de esas operaciones y realizar, en fin, en nombre de la Sociedad, con toda clase de personas y Entidades, cuantos actos y contratos autoricen las Leyes" (artículo 34, punto $7^{\circ}$ ). 
Figura 2. Estatutos de PALMATUR, aprobados el 26 de agosto de 1969.

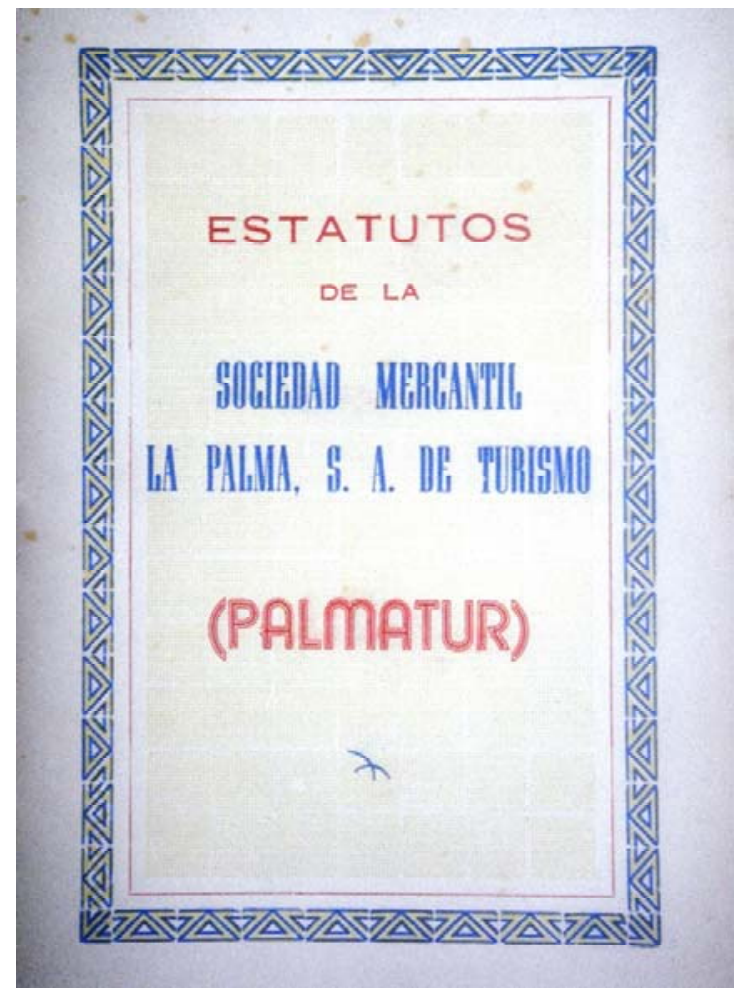

La Empresa preveía una inversión con destino a tres fuentes principales, quedando una marginal relativa a las primas o subvenciones de estímulo a la construcción, que en este último caso era de unos seis millones de pesetas, a saber:

1. La de las aportaciones de terrenos y bienes raíces, con una previsión de 55.650 .000 pesetas.

2. L a suscripción de capital para su desembolso en efectivo, con una cantidad de 128.550 .000 pesetas.

3. La de los préstamos a obtener del Crédito Hotelero y demás entidades de crédito oficiales y turísticas, con un monto de cien millones de pesetas.

En total, sumaban algo más de 290 millones de pesetas que serían financiados a su vez por tres fuentes principales:

1. La iniciativa privada, tanto interior como exterior, con la aportación de los mentados 128 millones de pesetas.

2. El crédito hotelero.

3. Las primas a la construcción que concedía el propio Cabildo. 
De hecho, los esfuerzos para que llegaran inversores a la Isla no solo se limitaron a los ciudadanos españoles, sino también de otros países, especialmente de Alemania, ya que desde 1968 estaban siendo incentivadas las inversiones en el exterior por el Ministro de Hacienda de aquel país, el señor Strauss ${ }^{8}$, además del capital procedente de América. En efecto, según recogemos de las declaraciones del Vicepresidente de PALMATUR, el señor Alcina, desde hacía escasas fechas, la entidad palmera ya era miembro "de la Cámara de Comercio Americana en España. Lo interesante, es que está vinculada a Washington, y las peticiones pasan a una entidad que atiende a la oferta de capitales para invertir en Europa" (Costa Canaria, 30/12/1969).

Las Bases para un proyecto de planificación y promoción turística de la isla de La Palma y PALMATUR tuvieron una incidencia modesta en el desarrollo turístico de la isla. Entre sus proyectos de más envergadura cabe citar el hecho de que intentara relanzar un hotel de más de 600 camas en la playa de Los Cancajos (El Eco de Canarias, 06/10/1971). Por tanto, a diferencia de lo que ocurrió en otras islas como Lanzarote o Gran Canaria (Hernández Luis y Parreño Castellano, 2001; González Morales y Hernández Luis, 2005), la política impulsada por el Cabildo no logró que La Palma se sumara a la lista de destinos turísticos de masas desde finales de los sesenta.

\section{El escaso desarrollo de la iniciativa privada}

La principal inversión privada en materia turística en los años sesenta en La Palma se canalizó hacia la construcción de algunos alojamientos turísticos. Entre ellos deberíamos destacar los hoteles Mayantigo y El Cisne, sin olvidar la urbanización Celta. El escaso número de alojamientos construidos y la multiplicación de otros que no llegaron a culminarse, como los hoteles Gazmira, o los de Puerto Naos o El Time, ponen de manifiesto el escaso interés que la iniciativa privada tuvo por la Isla debido a las complicadas condiciones para culminar y rentabilizar las inversiones. En este sentido, los continuos traspasos de propiedades y los dilatados procesos de construcción en el tiempo, son un buen ejemplo de las dificultades que las iniciativas turísticas privadas tuvieron en La Palma en ese periodo, a lo que habría que sumarle los obstáculos que los proyectos públicos tuvieron para llevarse a cabo.

Una de las primeras iniciativas privadas, la del hotel Mayantigo, que se levantó en Santa Cruz de La Palma en marzo de 1961, es un claro ejemplo de la falta de rentabilidad y los continuos traspasos intersocietarios que ésta originaba. Situado sobre un edificio propiedad del Banco Español de Crédito, en el que éste había dispuesto sus oficinas, fue construido por el farmacéutico D. Vicente Capote Herrera

8 Se trataba de la Ley Fiscal sobre Ayuda a Países en Desarrollo, promulgada en Alemania en marzo de 1968 por el mencionado Ministro Federal de Hacienda, señor Strauss, y con vigencia hasta finales de 1972. En este periodo, se estima que el capital alemán que llegó a Canarias fue de unos 70 mil millones de pesetas corrientes, invertidos casi en su totalidad en el sector turístico (Gaviria, 1974). 
en sociedad con su hija (Pérez García, 2009), para formar parte de la empresa compuesta por los hoteles Mayantigo y Florida, ambos en Santa Cruz de La Palma. El hotel disponía de 40 habitaciones (56 camas), lo que lo convertía en la infraestructura hotelera de mayor capacidad de la Isla. Bien es verdad que, en enero de 1963, el Director del hotel, Señor del Río, argumentaba los buenos resultados de explotación en estos términos: "Venimos recibiendo viajeros que traen prevista una estancia de dos o tres semanas. (...) La empresa Mayantigo - Florida tiene un contrato con una agencia de Alemania que garantiza un lleno del Florida al 100 por ciento y un 50 por ciento para el Mayantigo, durante un año" (Diario de Avisos, 14/01/1963), pero lo cierto es que la rentabilidad esperada no perduró en el tiempo.

En septiembre de ese mismo año fue traspasado a HORESA (Hoteles y Residencias, $S$. A.), propiedad del grancanario D. Fernando Navarro Galván, que en aquel entonces ya disponía de once hoteles en el Archipiélago. En 1966 se traspasó de nuevo, argumentándose por el anterior propietario la falta de conexiones de calidad con el exterior como el principal cuello de botella para la llegada de los turistas.

Otro ejemplo claro de falta de rentabilidad es lo ocurrido con el hotel Los Cisnes y la urbanización Celta, en el que el proceso de construcción y ampliación se eternizó en el tiempo ante las malas perspectivas inversoras. En el caso del hotel Los Cisnes, su inauguración parcial tuvo lugar en julio de 1963 en el municipio de El Paso, en un paraje aislado que el propietario, D. Clemente Gonzalvo Capote, vendía además en parcelas para la construcción de bungalows. La paulatina construcción del hotel se fue prolongando durante toda la década, hasta anunciarse en 1972 que el alojamiento alcanzaría las 200 camas, aunque ahora bajo la denominación de hotel Valle Sol (Diario de Avisos, 20/09/1972).

La urbanización Celta empezó a edificarse en 1967, en el Oeste de la Isla, en concreto en el municipio de El Paso. El proyecto estaba destinado a albergar turistas de larga estancia, de varios meses, preferentemente de invierno, cuando las condiciones climáticas eran más extremas en Europa. La urbanización se planificó para más de cien apartamentos y 180 bungalows, vendiéndose o alquilándose los primeros inmuebles al año siguiente. La urbanización fue retrasándose en el tiempo y hasta los setenta no tuvo un elevado nivel de materialización. A pesar de todo, podemos considerarlo como un complejo relativamente exitoso en comparación otras iniciativas pues, reiteramos, el modelo turístico era de largas temporadas y no de corta estancia donde la exigencia sobre el transporte exterior es máxima.

Entre los hoteles más importantes que no se materializaron, aunque comenzaron sus obras, apreciándose incluso en la actualidad su estructura, tenemos el hotel Gazmira, prácticamente en el centro urbano de Los Llanos de Aridane. Realmente el complejo, diseñado para unas 80 habitaciones de alta categoría, se gestó a finales de los años cincuenta y comienzos de los sesenta. Su arquitecto, D. Rubens Henríquez, conjuntamente con el entonces Alcalde del municipio, D. Manuel Pérez Acosta, fueron los grandes promotores de tal empresa. El Hotel comenzó las obras en septiembre de 1961 pero ya en la Junta General Extraordinaria de la Sociedad del 09 de diciembre de 1963, se acordó la enajenación de los bienes de la Comunidad. En 
este caso hay que destacar que el fracaso empresarial afectó a gran parte de la población local debido al modo de captar fondos para su construcción a través del capital popular, con la puesta en circulación de cientos de acciones de 3.000 pesetas cada una (Diario de Las Palmas, 16/09/1961), algo que terminaría siendo un referente para otros hoteles que se edificarían en otras islas y en el resto del Estado.

Otro ejemplo característico de proyecto hotelero fallido fue el hotel El Time. Desde los años treinta se manejaba la idea de ubicar un hotel en la zona de El Time, en un enclave con vistas privilegiadas al Valle de Aridane y al Parque Nacional de La Caldera de Taburiente (El Tiempo, 11/03/1936), si bien no fue hasta mediados los años sesenta, cuando en este paraje comenzó a consumarse la idea de construir un parador - mirador, acompañado de una sala de fiestas. Todo ello se recogía en un suplemento especial de más de 40 páginas, dedicado íntegramente al turismo en la isla de La Palma y editado en junio de 1965, por el periódico Diario de Avisos. Las obras de este hotel de ocho plantas, proyectado para albergar unas 100 camas, comenzaron a finales de 1966, estando muy avanzada la primera planta en el primer trimestre del año siguiente (Diario de Avisos, 12/04/1967). Sin embargo, tal empresa no pasaría de la citada primera planta, inaugurándose ésta como bar - restaurante y sala de fiesta en enero de 1968, encontrándose en explotación en la actualidad.

Por citar un tercer caso que acredite las dificultades para culminar los proyectos turísticos privados, mencionaremos el ejemplo de la Sociedad "Las Vegas, S. A.", entidad radicada en el Puerto de La Cruz y que ya explotaba varios hoteles en Tenerife (González Lemus, 2010), pues ésta adquirió una gran parcela en Puerto Naos para edificar allí un hotel con capacidad para casi 200 camas a mediados del años 1965. Las obras comenzaron bien avanzado el año 1967, argumentándose a finales del año siguiente, ya con una estructura de cuatro plantas, que su terminación era muy ardua, no por falta de capitales, sino por la necesidad de mejorar los accesos terrestres, así como los problemas con el fluido eléctrico y el agua, destacándose sobre todo -y una vez más-, el cuello de botella del viejo aeropuerto de Buenavista (Canarias Gráfica, 01/11/1968). Posteriormente, la parcela, con las obras inacabadas del hotel, sería adquirida por la empresa La Palma Development Company en 1972, proponiéndose entonces alcanzar las 520 camas, aunque no se llegó a realizar obra alguna hasta que fue derribada la estructura y se construyó un nuevo hotel a finales de los años ochenta.

\section{Causas del fracaso del modelo turistico en los años sesenta}

En los dos epígrafes anteriores se ha puesto de manifiesto, a partir del análisis de los proyectos, el escaso éxito de las iniciativas en los años sesenta y comienzos de la siguiente década, para el desarrollo de La Palma como destino turístico. Es sin embargo, en estos lustros, en los que se consolida en otras islas del Archipiélago el modelo turístico de masas. Las razones de este fracaso son muy dispares y, en gran medida, la lectura de los proyectos ya nos hace percibir cuáles fueron los principales 
factores. De todos ellos, queremos destacar dos hechos determinantes: la competitividad de la actividad primaria y la deficiente política de transportes.

\subsection{La rentabilidad de la actividad primaria}

La economía de La Palma se ha identificado históricamente con una potente actividad agraria. Y esto ha sido posible por múltiples factores, entre los que debemos subrayar las favorables condiciones del clima de la Isla, la fertilidad del suelo y, en especial, la gran disponibilidad de agua a un coste comparativamente bajo en relación con el resto del Archipiélago y, además, de muy buena calidad. También tendríamos que reseñar los importantes auxilios que la Isla recibió del Instituto Nacional de Colonización, sobre todo en los años sesenta, las remesas de los emigrantes de América o, entre otras, las múltiples obras de extracción y canalización del agua, aspectos todos ellos muy importantes para la agricultura de exportación, sobre todo del plátano (García Rodríguez, 1992; Rodríguez Brito, 1986).

En particular, destacaríamos la mencionada calidad y el precio del agua, uno de los recursos primordiales para la puesta en producción del plátano, pues si no hubiese sido por los obstáculos para la obtención de este elemento, es casi seguro que islas como Fuerteventura y Lanzarote también se hubiesen agregado desde el principio al cultivo de este producto y, en principio, con unas circunstancias bastante más propicias dadas las arduas condiciones de roturación en La Palma. En este sentido, el Centro de Investigación Económica y Social de la Caja Insular de Ahorros de Canarias, hacía hincapié en que La Palma "es la Isla en la que el agua tiene el precio más bajo, si bien solamente en la zona Norte muy abundante en aguas, es la que se paga a 1,40 Pts./m3. Existe sin embargo, un gran desequilibrio con la zona Sur en la que la media es de 3,00 Pts./m3. Cuando se ultimen las obras de los canales en marcha, se equilibrarán mucho más los precios en las dos zonas" (CIES, 1972). Y es que, en el sur de Gran Canaria, el precio del metro cúbico de agua tenía un coste un 85 por ciento más alto en relación con el fértil sotavento de La Palma.

Así pues, el mayor beneficio de la platanera en La Palma, condicionado especialmente por el inmejorable clima, la elevada calidad del agua, así como su bajo coste relativo, favoreció un beneficio por unidad de superficie de los más altos del Archipiélago. En estas circunstancias, la producción platanera en la Isla aumentó un 75 por ciento entre 1964 y 1974, mientras la producción de las otras islas permanecía estancada o incluso retrocedía (CIES, 1972; CIES, 1975). Como resultado, entre 1941 y 1970, el municipio de Los Llanos de Aridane, casi triplicó la superficie dedicada a este último cultivo, ya que pasó de las 175 a las 500 hectáreas. A su vez, la municipalidad de Tazacorte, cuadruplicó la cantidad inicial en el mismo periodo, pasando de 113 a 400 hectáreas (Rodríguez Brito, 1986).

Se puede argumentar pues, que La Palma era en esta etapa una Isla fuertemente vinculada a una agricultura de exportación que, además estaba altamente capitalizada. En 1970, la producción de plátanos por habitante en esta Isla era de 1.208 kilogramos; triplicando la ratio de Tenerife y Gran Canaria (CIES, 1972). Se comprende pues, que 
aun siendo importante la diversificación económica, La Palma contaba con un sustrato capaz de sostener a su población con un nivel de bienestar aceptable y, además, con un amplio minifundio que permitió repartir la riqueza generada por el plátano.

Este conjunto de razones fue un factor que impidió el paso de tierras desde el sector agrario al turístico. Solamente cuando el sector de plátano canario perdió el monopolio del mercado peninsular y su rentabilidad se puso en entredicho, el turismo como alternativa económica empezó a consolidarse, algo que no ocurrió hasta la década de los ochenta.

\subsection{El hándicap del transporte exterior}

La vinculación entre el transporte y el turismo es vital para los espacios insulares. La Palma es un ejemplo claro, pues en los años sesenta la ausencia de una ordenada política de transportes supuso un obstáculo insalvable para el desarrollo turístico.

En efecto, a finales de los cincuenta, cuando comenzó a plantearse el desarrollo turístico de La Palma, ésta contaba con un aeropuerto situado en Buenavista, al este de la Isla, con una pista de solo 900 metros de longitud. En ese momento se registraban tres vuelos a la semana con Tenerife y en pequeñas aeronaves de 28 plazas. Muy pronto se demostró que la climatología impedía el normal desarrollo del tráfico $^{9}$, a la vez que físicamente era imposible ampliar la pista, pues se encontraba flanqueada por dos profundos barrancos. Así pues, en 1961, es decir, solo seis años después de la inauguración de este aeropuerto, se dio a conocer un estudio de localización de nuevas pistas de vuelo alternativas ${ }^{10}$. La opción elegida fue la costa de Mazo, sobre todo por su climatología, ausencia de grandes obstáculos y futura accesibilidad viaria.

A pesar de que era necesaria para la Isla la construcción de un aeropuerto que permitiera el tráfico de mayores aeronaves, el aeropuerto de Mazo se terminó inaugurando en abril de 1970, con una longitud de pista de 1.700 metros aunque con posibilidades de ampliaciones futuras.

La construcción del nuevo aeropuerto de Mazo fomentó un gran ambiente en $\mathrm{La}$ Palma a favor del turismo. Así se reconocía en una cita de la excelente revista turística "Costa Canaria”, al afirmarse allí que:

Las noticias del lanzamiento de la isla de La Palma a la panorámica turística, coinciden con el momento en que las obras de su nuevo aeropuerto entran en la última fase, para poner punto y final a los posibles inconvenientes del transporte. (...) Y ahora sí, ahora sí se ha puesto en marcha la gran máquina para que la isla de La Palma

9 En el primer semestre de 1962 se cancelaron 82 vuelos debido a la meteorología, esto es, el 22.6 por ciento de las frecuencias (Organización Sindical, 1963).

10 Este estudio anónimo consta de unos 14 folios mecanografiados y lo hemos rescatado del Archivo General del Cabildo Insular de La Palma. 
quede definitivamente incorporada al mundo del turismo, haciendo su entrada en él por la puerta grande (Costa Canaria, 26/12/1968).

$\mathrm{Y}$ es que se argumentaba que la nueva pista de vuelo, de unos 1.700 metros de longitud, podía ser suficiente para la llegada de aeronaves como el Caravelle o el DC9, con lo que La Palma podría quedar en el radio operativo de estos aviones desde los países europeos.

Sin embargo, con estas condiciones el nuevo aeropuerto sirvió únicamente para regularizar el tráfico con el resto de las islas del Archipiélago. El desarrollo de vuelos chárter requería de una ampliación mayor de la instalación aeroportuaria.

Estas posibilidades de desarrollo ya estuvieron en el punto de mira desde el principio con el justificante turístico de trasfondo. Así, antes incluso de la inauguración del aeropuerto, en concreto en 1969, el Cabildo Insular encargó la redacción de un anteproyecto en el que se mencionaba la necesidad de prolongar la pista en 600 metros más ${ }^{11}$. Posteriormente, en 1975, se redactó un plan de ampliación, destacándose la constante alusión al incremento de longitud de la pista de vuelo de Lanzarote en 1970, pues se decía que el tipo de tráfico de esta Isla "es análogo al que se pretende para La Palma y que también tiene un potencial turístico alto"12. Así pues, en ese entonces se llegó a vaticinar que el aeropuerto de Mazo podría alcanzar los 5.6 millones de pasajeros en el año 1983 (y desde el punto de vista pesimista: 1.2 millones), cifra esta última que no se logró hasta 2007. En síntesis, las exiguas conexiones aéreas fueron uno de los factores claves del tardío desarrollo turístico de la Isla.

Por su parte, aunque el transporte marítimo no presentaba graves problemas de índole infraestructural en la década de los sesenta, sí los tenía en relación con las conexiones con el resto del Archipiélago, caracterizado por los prolongados tiempos de viaje y el mal estado de las embarcaciones. Fruto de ello fue la constante petición de mejoras por parte del Cabildo Insular, especialmente en tema de horarios y frecuencias con Tenerife.

\section{Conclusiones}

La sociedad de la isla de La Palma realizó notorios esfuerzos con el fin de desarrollar la actividad turística en los años sesenta. En este sentido, tanto las inversiones públicas, como las privadas, mostraron especial interés por el turismo y, todo ello, en un contexto donde la rentabilidad del cultivo de la platanera era de las más elevadas

11 Memoria del proyecto de eliminación de obstáculos en el Monte Goteras, suscrito por D. Carlos Ceballos Díaz, XII/1975, Archivo General del Cabildo Insular de La Palma.

12 Memoria del anteproyecto de ampliación de la pista de vuelo en el aeropuerto de La Palma - Mazo, suscrito por D. Ignacio Estaun Díaz de Villegas y D. Sebastián Pérez González, IV/1975, Archivo General del Cabildo Insular de La Palma. 
del Archipiélago. De todos modos, esta alta rentabilidad no fue exclusivamente el principal problema para que no se desarrollase el turismo en la Isla, sino las inseguras y escasas conexiones con el exterior, como así lo demostraban las paralizaciones de los hoteles más emblemáticos que se empezaron a construir en los años sesenta (el Gazmira, el Time y el de Puerto Naos).

$\mathrm{Al}$ amparo de esta circunstancia, las administraciones públicas impulsaron el turismo en La Palma iniciando la construcción de un segundo aeropuerto en poco más de una década, mejorando carreteras turísticas -en especial proporcionándoles pavimento asfáltico-, pero también ordenando varios proyectos urbanísticos para el turismo ("La Palma y el Mar" en el Este de la Isla y los de la "Costa de Tazacorte” y el de la "Costa Gris” en el Oeste). Estas últimas urbanizaciones recibirían el respaldo de la política del Cabildo Insular que, en 1968, promulgó las "Bases para un proyecto de planificación y promoción turística de la isla de La Palma", así como la presentación, un año más tarde, de la empresa pública: "La Palma, Sociedad Anónima de Turismo (PALMATUR)".

Por su parte, la iniciativa privada arriesgó sus capitales desde una fecha relativamente temprana, pues en 1961 se inauguró el hotel Mayantigo, convirtiéndose entonces en el de más capacidad de La Palma. En la vertiente occidental, se inauguró en 1963 el hotel El Cisne, al tiempo que se terminaban decenas de bungalows en la urbanización Celta para el turismo estacional. De todos modos, un importante monto quedó en los inacabados hoteles más arriba mencionados, detectándose cierta especulación con las parcelas que albergarían las tres grandes urbanizaciones antes citadas.

\section{Bibliografía}

Almeida García, F. (2012): La política turística en España y Portugal. Cuadernos de Turismo, 30, 9-34.

Bayón Mariné, F. (1987): Legislación turística española. Madrid, Ed. Civitas.

Bayón Mariné, F. (ed.) (1999): 50 años del turismo español, un análisis histórico y estructural. Madrid, Centro de Estudios Ramón Areces, S. A.

Blasco, A. (2001): Turismo y transporte. Madrid, Ed. Síntesis.

Cals Güel, J. (1974): Turismo y política turística en España: una aproximación. Barcelona, Ed. Ariel.

Casanova, L. (1970): Urbanismo y turismo. La experiencia española. Madrid. Consejo Superior de los Colegios de Arquitectos.

CIES (1972): Aspectos estructurales del sector platanero de Canarias. Boletín no 13. Las Palmas de Gran Canaria, Ed. Centro de Investigación Económica y Social de la Caja Insular de Ahorros de Gran Canaria.

CIES (1975): Economía canaria 73 y 74. Boletín nº 20. Las Palmas de Gran Canaria, Ed. Centro de Investigación Económica y Social de la Caja Insular de Ahorros de Gran Canaria. 
Esteve Secall, R. y Fuentes García, R. (2000): Economía, historia e instituciones del turismo en España, Madrid, Ed. Pirámide.

Faraldo Jarillo, J.M. y Rodríguez-López, C. (2013): Introducción a la historia del turismo, Madrid. Ed. Alianza.

Fernández Fúster, L. (1991): Geografía general del turismo de masas. Madrid, Alianza Ed., Colección Alianza Universidad Textos.

Galiana Martín, L. y Barrado Timón, D. (2006): Los centros de interés turístico nacional y el despegue del turismo de masas en España. Investigaciones Geográficas, 39, 73-93.

García Rodríguez, J.L. (1992): Emigración y agricultura en La Palma. Santa Cruz de Tenerife, Ed. Consejería de Agricultura y Pesca del Gobierno de Canarias y Excmo. Cabildo Insular de La Palma.

Gaviria, M. et al. (1974): España a go-gó. Turismo charter y neocolonialismo del espacio. Madrid, Ed. Turner.

González Lemus, N. (2010): El turismo en la historia del Puerto de la Cruz, a través de sus protagonistas, Puerto de la Cruz, Ed. Escuela Universitaria de Turismo Tomás Iriarte.

González Lemus, N. et al. (2012): El viaje y el turismo en Canarias: evolución histórica y geográfica. Las Palmas de Gran Canaria, Ed. Anroart.

González Morales, A. y Hernández Luis, J.Á. (2005): El desarrollo del turismo en Lanzarote. Santa Cruz de Tenerife, Ed. Idea (2 tomos).

Hernández Luis, J.Á. y Parreño Castellano, J.M. (2001): Evolución e implicaciones del turismo en Maspalomas, Costa Canaria, Ed. Ayuntamiento de San Bartolomé de Tirajana.

Hernández Luis, J.Á. (2008): El turismo de masas. Evolución y perspectivas. Madrid. Ed. Síntesis.

Martín Martín, V. O. (2000): El turismo en el Sur de Tenerife: de la renta agraria a la renta del ocio, Santa Cruz de Tenerife, Ediciones del Cabildo de Gran Canaria y Cabildo de Tenerife.

Moreno Garrido, A. (2007): Historia del turismo en España en el siglo XX. Madrid, Ed. Síntesis.

Murray, I. (2015): Capitalismo y turismo en España. Del "milagro económico" a la "gran crisis". Barcelona, Alba Sud Editorial.

Organización Sindical (1963): Canarias: anexo al Plan de Desarrollo Económico y Social, años 1964 a 1967. Separata quinta (Turismo y Transportes), Las Palmas de Gran Canaria.

Pellerejo Martínez, c. (1999): Historia de la economía del turismo en España, Madrid, Ed. Civitas.

Puertas, X. (2007): Historia del turismo en España en el Siglo XX. Madrid, Ed. Síntesis.

Rodríguez Brito, W. (1986): La agricultura de exportación en Canarias (1940 - 1980). Santa Cruz de Tenerife, Ed. Consejería de Agricultura, Ganadería y Pesca del Gobierno de Canarias.

Rodríguez Mateo, A. (1992): Historia del turismo español a través del derecho. Ed. Universidad de Las Palmas de Gran Canaria. Las Palmas de Gran Canaria.

Terán Troyano, F. (1978): Planeamiento urbano en la España contemporánea. Madrid, Ed. Alianza. 
Vallejo Pousada, R. (2002): Economía e historia del turismo español del siglo XX. Historia Contemporánea, 25, 203-232.

Velasco González, M. (2004): La política turística. Gobierno y administración turística en España (1952-2004). Valencia. Fundación Cañada Blanch. 
Anales de Geografía de la Universidad Complutense ISSN: 0211-9803

http://dx.doi.org/10.5209/rev_AGUC.2016.v36.n1.52715

\title{
Reorganización administrativa territorial como estrategia para optimizar la estructura de la Administración local
}

\author{
Tomás Llorente Aguado ${ }^{1}$; Jesús Molina Saorín ${ }^{2}$ \\ Recibido: 23 de septiembre del 2015 / Enviado a evaluar: 23 de enero del 2016 / Aceptado: 3 de mayo del 2016
}

Resumen. Durante la durísima experiencia económica, social y de falta de valores que se ha atravesado en los últimos años, las Administraciones públicas -especialmente en Grecia, Portugal, Italia y Españase han visto obligadas a reconsiderar fuertemente la estructura y el tamaño de su sector público. A pesar de algunas iniciativas encaminadas a reducir el número de municipios y provincias, pocos avances sustanciales se han producido en la mejora de la gestión de la Administración pública local durante esta crisis. En este estudio se propone la reorganización administrativa territorial como estrategia para optimizar la estructura de la Administración local, analizando la situación española -en general- y de una comunidad autónoma en particular.

Palabras clave: Administración pública; eficiencia; ordenación territorial; competencias públicas.

\section{[en] Territorial administrative reorganization as a strategy for optimizing the structure of local government}

\begin{abstract}
Through the tough economic and social situation and the lack of values that has been experienced in recent years, local governments especially in Greece, Portugal, Italy and Spain have been forced to strongly consider the structure and size of their public sector. Despite some initiative to reduce the number of municipalities and provinces, little substantive progress has been made in improving the management of the local public Administration during this crisis. In this study a territorial administrative reorganization is proposed as a strategy to optimize the structure of local government, analyzing the Spanish situation in general, and an autonomous community in particular.
\end{abstract}

Keywords: Public Administration; efficiency; territory organization; public competences.

1 Ayuntamiento de Abarán (Murcia)

E-mail: 14555llorente@coam.es

2 Universidad de Murcia

E-mail: jesusmol@um.es 